\title{
autêntica
}

\author{
ARTIGOS
}

\section{Pesquisa em rede e a formação do pesquisador em educação: uma experiência do Observatório da Educação (Obeduc) UECE/UFOP/UNIFESP}

Isabel Maria Sabino de Farias - UECE José Rubens Lima Jardilino - UFOP Magali Aparecida Silvestre - UNIFESP Financiamento CAPES

\begin{abstract}
RESUMO
Este artigo apresenta uma reflexão sobre a contribuição da Pesquisa em Rede para a formação do professor pesquisador em Educação. Teve como apoio o financiamento do Programa Observatório da Educação OBEDUC/CAPES1, iniciativa que promove, de modo integrado, a produção de conhecimento sobre a Educação Básica e a formação do pesquisador dessa área. É uma iniciativa com forte potencial indutor da melhoria da formação do professor, tendo como esteio o princípio da aproximação e da interlocução universidade e escola pública. Igualmente, representa ação que favorece a sistematização de conhecimentos de temas e pontos pulsantes na cena educativa nacional escolar, a exemplo do desenvolvimento dos professores e da inovação nas práticas de ensino. A reflexão aqui posta faz considerações sobre a relevância da pesquisa na formação de professores, registrando depoimentos de docentes da Educação Básica participantes de investigação em rede e a relevância em termos de formação continuada e os respectivos impactos no desenvolvimento profissional dos professores da Escola Básica, participantes da pesquisa.
\end{abstract}

\section{PALAVRAS-CHAVES}

Formação de Professor, Rede de Pesquisa/Formação, Professor pesquisador.

\section{NETWORK RESEARCH AND EDUCATION RESEARCHER TRAINING}

ABSTRACT: This article presents a reflection on the contribution of the Network Research for the training of research professor in Education. It has been supported by the funding of the Observatory Education Program - OBEDUC / CAPES, an initiative that promotes, in an integrated way, the production of knowledge about Basic Education and the training of the researcher in this field. It is an initiative with strong potential to induce the teacher, having as a mainstay the principle of the approach and interlocution university and public school. Likewise, it represents an action that favors the systematization of knowledge of themes and pulsating points in the national school educational scene, such as the development of teachers and innovation in teaching practices. The reflection put forward here makes considerations about the relevance of the research in the training of teachers, recording testimonies of teachers of Basic School participants in network research and the relevance in terms of continuing education and the respective impacts on the professional development of the teachers of the Basic School, participants of the research.

KEYWORDS: Teacher Training, Research / Training Network, Researcher Professor.

1 Esse texto que ora apresentamos a Revista Brasileira de Pesquisa sobre Formação de Professores - Formação Docente - é fruto de uma longa discussão que os autores vêm acumulando nos últimos quatro anos, em decorrência de uma experiência de Pesquisa sobre Formação de Professores em Rede. Naturalmente, parte desse material, já circulou em outros artigos, mesas, colóquios e debates em eventos da Área em que tomamos parte para apresentar a pesquisa. Mais especificamente nos referimos a apresentação pública da Pesquisa como trabalho encomendado do GT 08- Formação de Professores na Reunião Nacional da ANPED/Maranhão 2017. E, ao artigo "Contribuições do OBEDUC como pesquisa em rede para a formação do professor” (FARIAS, JARDILINO e SILVESTRE, 2016), publicado na Revista Educação Matemática em Foco, v.5, nº1, jan., 2016 , p. 13-29. 


\section{autêntica}

\section{A IDEIA DE “REDES” NA SOCIEDADE CONTEMPORÂNEAS: DIALOGANDO COM ALGUNS DE SEUS INTERPRETES.}

A noção de rede evoca, de acordo com o Dicionário Houaiss da Língua Portuguesa (HOUAISS e VILLAR, 2009, p. 1.627), a ideia de entrelaçamentos, de um "conjunto de pontos que se comunicam entre si" ou de "pessoas, órgãos ou organizações que trabalham em conexão, com um objetivo comum".

A ideia de rede ${ }^{2}$ formulada pela emergência das tecnologias contemporâneas torna-se uma imagem sui generis para representar o conhecimento no mundo contemporâneo no qual se consolida mais e mais um novo paradigma para a ciência e o conhecimento. Desta forma a ideia de rede foi inspirada, em grande parte, na insurgência das tecnologias informacionais e na percepção de que ninguém pensa sozinho, uma vez que todo pensamento é nó e trama de uma rede de conhecimentos e relações.

Na perspectiva acima, temos o conceito de Sociedade em Rede concebido por Manuel Castell (2002) que se caracteriza por um tipo de sociabilidade assentada numa dimensão virtual, impulsionada pela ascensão das chamadas 'novas tecnologias' redimensionaram o tempo e o espaço do que conhecemos desde a modernidade. Assim o termo rede ganha significado nas interações entre os sujeitos no mundo pós-internet.

Conforme os mais afoitos na onda mystique et ésotérique ${ }^{3}$ das tecnologias da informação, erroneamente denominada como sociedade do conhecimento (uma vez que a informação não é conhecimento per si. Para se transformar em conhecimento precisa da imprescindível mediação do homo sapiens), a Sociedade em Rede é uma "entidade" que transcende e atravessa a sociedade do conhecimento e da informação. Com o rompimento das dimensões de tempo e de espaço modernos a sociedade em rede se organiza a partir de elementos conexos entre os sujeitos que exigem a reconceituação de tempo e espaço, onde as fronteiras físicas não são mais fatores sine qua non na difusão do conhecimento e dos demais fatores do homem na sociedade global, como foi denominada por McLuhan (Data).

Nesta perspectiva, conhecer é como enredar, tecer significações, partilhar significados. Os significados são construídos na inter-relação com objetos, as noções, os conceitos, nos quais sujeitos cognoscentes e objetos participam, no mesmo plano da construção do conhecimento. Essa concepção rechaça por completo a construção cartesiana de conhecimento e, portanto, está em sintonia com um novo paradigma de conhecimento. Um significado é como um feixe de relações. O significado de algo é construído falando-se sobre o tema, estabelecendo conexões pertinentes, às vezes insuspeitadas, entre diversos temas. Esses feixes de relações, por sua vez, articulam-se em uma grande teia de significações e o conhecimento é fruto dessa engrenagem cognoscente, socialmente construído.

Uma das características das redes de conhecimento é a heterogeneidade. A imagem da rede continuamente nos lembra de que os nós/significados são naturalmente heterogêneos, no sentido de que envolvem relações pertencentes a múltiplos conteúdos, a diversas disciplinas. As noções, os conceitos realmente relevantes, sempre terminam por ultrapassar as fronteiras disciplinares, como desejou Morin (Data), quase chegando a trasndisciplinariedad.

No campo educacional, cada vez mais a noção de rede vem se constituindo como uma estratégia marcante para superarmos o velho paradigma do conhecimento centrado basicamente na autoria solitária do pesquisador.

2 Acerca da concepção de rede, Latour (2000) propõe que essas possibilitem interações que formariam uma teia de aliados para saber mais, saber o não sabido, proporcionando acesso a novas construções.

3 Castell (2005) considera a Sociedade em Rede como um estágio superior do desenvolvimento humano 
Não é atoa que até muito pouco tempo, nos diversos campos da área, os grupos de pesquisas resumiam-se quase grupo/mono, ou seja, um pesquisador e seus pupilos, talvez como reminiscência das velhas Cátedras universitária nas quais um "madarin" dirigia uma equipe de estudantes ao seu mestre ligado umbilicalmente. Somente, muito recentemente, na área da pesquisa, tem sido um requisito fomentado pelas agências de financiamento, a exemplo do CNPq que, para incentivar a criação de redes de pesquisa, informa em sua página que "estas visam impulsionar a criação do conhecimento e o processo de inovação resultantes do intercâmbio de informações e, sobretudo, a junção de competência de grupos que unem esforços na busca de metas comuns... Esses buscam suprir a necessidade de um ambiente próprio e especializado em uma determinada área do conhecimento."

\section{A PESQUISA EM REDE NA FORMAÇÃO DE PROFESSORES: UMA EXPERIÊNCIA NO OBEDUC.}

Esta compreensão, entre outros fatores, serve de esteio à indução de políticas abrangentes, como o Programa Observatório da Educação (OBEDUC), uma das ações implementadas em 2006 pela CAPES/INEP, visando a robustecer a formação inicial e continuada de profissionais da Educação Básica . Entre os objetivos dessa iniciativa, se destacam a produção de conhecimento sobre a Educação Básica e a formação de pesquisadores para a área, conforme enfatiza matéria registrada no sítio eletrônico dessa agência: "Obeduc se firma como programa de estímulo a pesquisas voltadas à formação de recursos humanos em educação".

A articulação entre pós-graduação e Educação Básica caracteriza o OBEDUC, beneficiando mestrandos, doutorandos, graduandos e professores da escola vinculados a rede pública de ensino, agregados em torno de propostas de pesquisa, individuais ou em rede, selecionadas por meio de edital e apresentadas por Programas de Pós-Graduação e grupos de pesquisa (CLÍMACO, NEVES e LIMA, 2012). Em 08/06/2016, - OBEDUC completou dez anos, contabilizando até o momento cinco edições (2006, 2008, 2009, 2010 e 2012). De um conjunto de 28 projetos de pesquisa, em 2006, saltou para 176, em 2013 (136 projetos locais e 40 em rede), alcançando 212 programas de pós-graduação e concedendo 184 bolsas de doutorado, 491 de mestrado, 977 para professores da Educação Básica , 175 para coordenadores dos projetos e 1.019 para alunos de graduação (BRASIL.CAPES.DEB, 2013a, p.12).

Foi partindo dessa perspectiva que o Programa Observatório da Educação - OBEDUC, da Capes/Educação Básica fomentou uma linha de financiamento para pesquisas sobre a formação de professores e que essas pesquisas fossem realizadas em redes de universidades e grupos. Essa indução forçou os programas de pós-graduação a constituírem redes de grupos de pesquisadores para discutir e pesquisar a formação de professores, dialogando com os colegas que estão atuando na educação básica. Essas redes se constituíram em todo o país, a partir desse edital da Capes. No nosso caso, a rede constituída pela UECE, UFOP e UNIFESP demonstra sua experiência no âmbito dessa pesquisa. Pesquisa em rede porque assumida como ação de coletivo e de colaboração entre pares desde as decisões teóricas e metodológicas de fundo aos encaminhamentos mais operacionais em torno do objeto de estudo; pesquisa em rede movida pelo interesse de também contribuir para a formação de seus pesquisadores, iniciantes e veteranos.

A referida pesquisa foi se formulando espontaneamente, no entrelaçamento dos grupos e de experiências novidadeiras que surgiam pari passo, a despeito da experiência de seus coordenadores, em rede de pesquisa, já ambientada pelas discussões anteriores do campo, de que é necessário formar o professor num ambiente de pesquisa, ou melhor, formar o "professor pesquisador", tema amplamente discutido e consolidado como conhecimento indispensável para a temática. A pesquisa Desenvolvimento Profissional Docente e Inovação Pedagógica constitui-se numa grande rede de pesquisa e de formação com três núcleos orientados por 


\section{autêntica}

grupos de investigação consolidados. Ao reunir pesquisadores das universidades, doutores, mestrandos e doutorandos, alunos de graduação em experiência de Iniciação Científica e os professores pesquisadores da Escola Básica do Ceará, de Minas Gerais e São Paulo, esse projeto avançou numa experiência sui generis de Rede de Pesquisa para a Formação de Professores no Brasil. Essa experiência já faz parte do acervo do projeto em eventos e publicações de artigos e capítulos de livros (Faria, Silvestre, Jardilino, 2015, 2016) nos quais os autores narram e divulgam essa grande experiência formativa e de pesquisa.

Estabelecer uma metodologia de pesquisa, aqui entendida na acepção proposta por Minayo (1994, p. 16), como "caminho do pensamento e a prática exercida na abordagem da realidade" foi, desde a elaboração do Projeto, uma preocupação e uma busca, sobretudo em virtude do caráter multicêntrico da iniciativa. O percurso trilhado nos quatro anos de execução do Projeto "Desenvolvimento Profissional Docente e Inovação Pedagógica: estudo exploratório sobre contribuições do PIBID" demonstra que realizar uma investigação em rede não é tarefa simples, uma vez que cada contexto possui peculiaridades, as equipes são heterogêneas, com ritmos e condições distintas de trabalho. Estabelecer um compasso na agenda de pesquisa, respeitando as singularidades, constituiu um desafio. Nesse esforço, a adoção do planejamento coletivo anual das ações macro da pesquisa, envolvendo integrantes dos três núcleos, revelou-se uma estratégia fértil.

Nesse esforço, muito também contribuiu o suporte das tecnologias da comunicação e da informação, em particular a internet e suas múltiplas ferramentas que asseguraram aproximação real entre os núcleos na discussão de dados e definição dos procedimentos. A realização de reuniões utilizando-se a ferramenta do skype fortaleceu sobremaneira essa articulação, permitindo uma interlocução direta e vivaz entre pesquisadores postados em distintos lugares. Ademais, a experiência de realização de um trabalho em conjunto, compartilhando instrumentos e referencial teórico, ação que demanda um tempo maior do que em outras situações de pesquisa na tomada de decisões, se revelou importante na constituição de práticas colaborativas de pesquisa e na formação de jovens pesquisadores em Educação. Esta, certamente, é uma situação de pesquisa que favorece rupturas com práticas isoladas e centralizadas na produção de conhecimento.

Encontros ampliados de planejamento entre os núcleos, elaboração de agenda anual comum de trabalho, sessões de estudo, debates mediados pelo uso de recursos tecnológicos disponíveis na internet (skype e web conferências), realização de oficinas sobre temas e práticas de pesquisa (a exemplo do uso do software NVivo), produção de textos e discussão entre núcleos, são algumas das ações que conformaram a dinâmica de desenvolvimento desta investigação em rede. Mesmo considerando um grupo grande de pesquisadores e com diversidade, a equipe do Observatório firmou, no que concerne às questões teóricas e metodológicas da pesquisa, uma dinâmica de colaboração para trabalhar localmente e em rede, superando distâncias e assimetrias institucionais

Nesse caminho, inúmeros aprendizados (trabalhar com grupos heterogêneos um desafio constante); conquistas importantes (vários integrantes aprovados em concursos públicos e na pós-graduação, entre estes, professores da escola pública); interfaces férteis no fortalecimento de grupos de pesquisa e de programas de pós-graduação (participação em bancas, ações de solidariedade entre programas de pós-graduação, intercâmbio de docentes e estudantes e estímulo à inserção de professores da escola pública na pós-graduação stricto sensu) e na interlocução universidade/escola pública, bem como na produção de conhecimento em parceria na elaboração de artigos, organização de livros e comunicações visando a participação em eventos.

\section{PESQUISA COMO FORMAÇÃO: UMA CONVERSA QUE JÁ ACUMULA MUITA REFLEXÃO.}

A maioria das publicações que aborda a formação do professor está mais direcionada para a formação inicial, embora os ensaios e estudos sobre a formação continuada, aqui e ali, indiquem a pesquisa como elemento sine qua non na formação. Estas produções, em geral, decorrem de estudos realizados no âmbito de cursos de pós-graduação (lato e stricto sensu). 


\section{autêntica}

A discussão sobre essa temática surgiu intensamente nos anos 1990, embalada, sobretudo, pelas reformas educacionais que a América Latina vinha realizando. Obras com resultados de pesquisas estrangeiras desembarcam avassaladoramente em nossas plagas, tornando-se uma 'febre' entre os pesquisadores do campo no Brasil a leitura desses novos teóricos (a exemplo de Zeichner, Schön, Nóvoa), em especial, os filiados a uma concepção crítica aos modelos de formação e sob os quais se formam os professores daqui. Com esteio nesse diálogo com os colegas externos, reorientou-se o foco da pesquisa no campo da formação para atender preocupações locais de formar o professor visando ultrapassar a perspectiva de "dador de aula", como referido por Demo (2006). No Brasil, dentre muitos pesquisadores do campo que discutem a pesquisa como elemento fundamental para a formação de professor, merecem destaque Lüdke, André e Gatti, pioneiras em pesquisa sobre o tema.

A concepção de professor pesquisador, relacionada ao movimento de formação docente, tem sido difundida no Brasil nas últimas duas décadas, especialmente com pesquisas realizadas por André (1997; 2006a) e Lüdke (2001; 2006). Essas investigações destacam a importância e a necessidade da pesquisa sobre a formação e o trabalho do professor, além de assinalarem os desafios a serem ultrapassados no processo de preparação do professor pesquisador e no desenvolvimento da pesquisa na Educação Básica (ANDRE e PESCE, 2012, p.43).

É evidente que esse tema, e a intensa pesquisa que em torno dele se desenvolve, permitiu vislumbrar a formação de maneira a superar o modelo de formação tradicional que ocorria desde a constituição da preparação de professores na República. Não foi pouco o esforço dos pesquisadores do campo para demonstrar que a predominância de uma prática docente quase que unicamente pela via da transmissão de conteúdos, seja na escola básica como nos estudos superiores, não propiciava espaço pedagógico para o estudante desenvolver sua capacidade de reflexão crítica, o pensamento autônomo e o espírito científico e investigativo. Com base nessa experiência, pesquisadores do campo expõem o problema na legislação e nas práticas pedagógicas. Brzezinski (2005), Severino (2002) e Demo (2006), por exemplo, denunciam o fato de que há pouca ênfase para a atividade de pesquisa nos espaços de formação de professores.

Se na versão anterior das Diretrizes Nacionais para os cursos de formação de professores (BRASIL, 2002) já havia na legislação um indicativo de que a pesquisa deveria ser um componente da formação, embora, conforme os autores, isso não tenha se consubstanciado nas práticas formativas, as novas diretrizes curriculares nacionais (BRASIL, 2015) apontam mais incisivamente para este ponto. De acordo com Dourado (2015, p.305), as novas diretrizes curriculares nacionais para a formação inicial e continuada dos profissionais do magistério, no esforço de se ajustar ao tema, "contempla a articulação entre graduação e pós-graduação e entre pesquisa e extensão como "princípio pedagógico essencial ao exercício e aprimoramento do profissional do magistério e da prática educativa" (grifo nosso).

Na tentativa de superar a dicotomia em torno das questões e interpretações do professor pesquisador, André e Pesce (2012) destacam três concepções formuladas por pesquisadores estrangeiros (COCHRAN-SMITH e LYTLE, 1999) que têm a pesquisa como elemento primordial de formação.

A primeira concepção é denominada de "conhecimento-para-a-prática" (knowledege for practice), que pressupõe que os professores devem usar o conhecimento formal e as teorias desenvolvidas por pesquisadores acadêmicos para melhorar a sua prática. [...] Após aprender e dominar a base de conhecimento, o professor deve implementá-la e adaptá-la a fim de que o ensino ocorra com eficiência e controle. O professor não é visto como gerador de conhecimento nem capaz de teorizar sobre sua prática. A segunda concepção, "conhecimento-em-prática" (knowledege in practice), 


\title{
autêntica
}

\begin{abstract}
valoriza o conhecimento em ação. [...] O papel do professor é o de refletir, investigar e gerar conhecimento na ação, a fim de resolver problemas existentes na sala de aula. A terceira concepção, "conhecimento-da-prática" (knowledege of practice), entende que o professor aprende quando ele considera sua sala de aula um lócus de investigação. [...] O conhecimento produzido pelo professor surge da investigação sistemática do ensino, dos alunos e do aprendizado, assim como da matéria, do currículo e da escola. [...] O questionamento é feito sobre sua prática e sobre o conhecimento produzido por outros (teorias e pesquisas acadêmicas), sem negar a importância desse conhecimento. O papel do professor é de crítico na geração de conhecimento sobre a prática, conectado a grandes temas sociais, culturais e políticas. (ANDRÉ; PESCE, 2012, p. 42 passim).
\end{abstract}

Malgrado a importância desse tema para a formação, hoje em amadurecimento, as pesquisas começam a detectar a noção de que a pesquisa na formação transpõe o que se convencionou chamar "investigação da própria prática". Há necessidade de pensar na formação do professor pesquisador tendo como princípio a categoria científica. A dicotomia criada na adjetivação da categoria professor pesquisador - um que "pesquisa" a sua prática (diagnóstico, planejamento e tomadas de decisões para agir "na ação e pós à ação") e outro que vai realizar, no âmbito da pós-graduação ou de projetos em rede, pesquisa de cunho científico - não auxiliou muito os docentes em sua vida e prática profissional.

Ainda são precários e insatisfatórios os avanços no que diz respeito à pesquisa na formação, pois a legislação até agora mantém uma visão fragmentada de ensino e de pesquisa que acompanha a estrutura das propostas curriculares dos cursos de formação, especialmente no que diz respeito aos pressupostos teórico-metodológicos, não conseguindo ainda superar lacuna histórica na formação expressa no binômio "teoria e prática". Sem negar os avanços desse debate, o fato é que se continua a reforçar a existência de duas categorias de pesquisadores, inclusive com méritos acadêmicos diferenciados. Os primeiros são os praticum, e os outros os teórico-reflexivos.

Consoante se acompanha, essa dicotomia "entre o conhecimento trabalhado na academia e a realidade educativa na formação de professores, tem sido historicamente criticada pela incapacidade de estabelecer uma relação complementar entre teoria e prática" (GALIAZZI e MORAIS, 2002, p. 249, 251).

Zeichner (2000, p. 229-230) aposta na possibilidade de se lograr vencer a linha divisória entre professores da escola básica e pesquisadores acadêmicos. Uma das maneiras, segundo o autor, seria o esforço "nos processos de pesquisa, em desenvolver uma colaboração genuína com os professores rompendo com os velhos padrões de dominação acadêmica".

Nessa direção, a pesquisa acima referida foi se constituindo colaborativamente, somando-se à experiência de seus coordenadores em pesquisa e, paulatinamente, em uma rede investigativa que, já ambientada pelas discussões anteriores do campo de que é necessário formar o "professor pesquisador", transformou-se numa rede interinstitucional de pesquisa e de formação nos três núcleos mencionados.

Reporta-se, aqui, à formação de 29 professores ${ }^{4}$ pesquisadores que trabalham na escola pública de Educação Básica e participaram de pesquisa em rede apoiada pelo Programa Observatório da Educação (OBEDUC/ CAPES Edital 2012). Nessas três instituições, os professores das redes municipais e estaduais de cada

4 No Ceará todos os professores da Educação Básica beneficiados com bolsa do Observatório, um total de 11 docentes, realizaram, no período de vigência do projeto o curso de Mestrado em Educação. Desse universo, cinco ainda lograram êxito na seleção do curso de Doutorado, que se encontra em andamento. 


\section{autêntica}

Estado vivenciaram situações formadoras, incrementando seus conhecimentos teóricos e práticos acerca da metodologia científica, ou seja, se tornando professores pesquisadores apoiados no princípio da investigação científica.

Os professores da escola básica envolvidos na pesquisa nos três núcleos revelaram, de maneiras diferentes, como a formação de professores pesquisadores se constituiu. Todos indicam que o encontro com a pesquisa desde sua inserção numa rede enriquece e amplia suas experiências e práticas nesse campo, tanto teórica quanto empírica, constituindo-se num locus privilegiado de formação. Os fragmentos que seguem, extraídos dos relatos do grupo de colegas, professores pesquisadores da Educação Básica, que participam do Observatório, são ilustrativos desse movimento:

Os seminários são o ponto forte do projeto, as leituras de teses, textos acerca da profissão docente são, a cada momento, desencadeadas num leque de conhecimento da prática enquanto professor, que se evidencia a variedade de aprofundamento teórico na profissão (METIKO, 2015).

Nós percebemos com o anseio de sermos pesquisadoras, dar continuidade à nossa formação. Voltamos nosso olhar para nossas salas de aula com o desejo de transformá-las em verdadeiros lócus da tão sonhada educação de qualidade (BETH, 2015).

Como diz Paulo Freire, "Não há saber mais, nem saber menos, há saberes diferentes.." Eu começo a entender que por mais que você tenha a prática é com a teoria que você vai avançar nos conhecimentos. Ela te dá suporte, razão, confiança e, inclusive, o direito de discordar (JOEL, 2015).

Muitos desses "cursos", ao longo da carreira, pouco ou nada contribuíram para a minha formação profissional por não proporcionarem uma reflexividade crítica que permitisse a "(re)construção permanente de uma identidade pessoal e profissional" [...]. Nessa perspectiva, a formação pela pesquisa só faz sentido se for capaz de desencadear mudanças pertinentes e necessárias nas escolas (VERA, 2015).

Estes depoimentos chamam atenção para o fato de que é urgente e necessário fortalecer a pesquisa na formação inicial de professores, como apontou as DCNs, contudo, para aqueles que já estão na lida, há muito ou pouco tempo, a exigência de uma formação continuada associada a redes de pesquisas é de uma importância primordial. As críticas às oportunidades de educação continuada ofertadas pelos sistemas de ensino crescem pela voz dos professores (alvo dessas ações) e dos pesquisadores que investigam tais iniciativas e argumentam que esses processos carecem de articulação mais orgânica com o propósito de promover seu desenvolvimento profissional. Nesse sentido, parece pertinente se retomar a advertência de Rausch (2012):

É preciso entender que a pesquisa sobre a prática docente necessita da pesquisa como ciência. Ou seja, pesquisa é pesquisa em ambas as situações. A questão talvez seja que o objeto de investigação e a finalidade da pesquisa sejam outras. Porém é preciso entender que não se ressignifica substancialmente a prática docente somente observando, pensando e registrandose sobre ela, sem um processo estruturado que permite conhecer com profundidade a partir de um método que possibilite uma compreensão do objeto investigado. [...] Quando defendemos a pesquisa de professores da Educação Básica, é entendida como um processo de se fazer ciência, e em se tratando de professor pesquisador, um processo de se fazer ciência acerca da docência (RAUSCH, 2012, p.707-712). 


\section{autêntica}

Enfim, se há interesse em reforçar "a pesquisa de professores da Educação Básica [...] como um processo de se fazer ciência", faz-se necessário constituir políticas de Estado que priorizem a pesquisa na formação docente, inicial e continuada. Essa nos parece que, mesmo sendo uma política de governo, hoje em crise, foi a tentativa do Programa Observatório da Educação (OBEDUC/CAPES). Talvez precisássemos pensar verdadeiramente na constituição de um sistema de formação de professores no Brasil como uma política de Estado para não ficar susceptível as intempéries de crises político-econômica dos governos.

\section{PESQUISA EM REDE:- APRENDIZADOS DE UMA EXPERIÊNCIA.}

Um dos compromissos da pesquisa em rede foi realizar um levantamento sobre seus egressos, uma vez que, ao longo desses anos, contou-se com a participação de graduandos, mestrandos, doutorandos e professores da Educação Básica com distintas formações. Para isso, identificaram-se os egressos através do banco de dados da Capes, integrantes bolsistas e não bolsistas do Observatório nos três núcleos e se entrou em contato via e-mail ou, quando necessário, por telefone, solicitando que respondessem a um formulário eletrônico estruturado na plataforma do Google Drive.

Ao todo foram enviados 57 convites via internet. O formulário eletrônico foi constituído de 21 questões e estruturado em três blocos de perguntas: o primeiro, com dados pessoais de identificação, contendo nome, telefone, e-mail, idade, sexo, categoria e núcleo de participação no OBEDUC; no segundo, constam dados de participação no Observatório, com ingresso, tempo de permanência, motivo de participar, razão de desligamento, participação em eventos, apresentação de trabalhos e experiências marcantes durante a participação na pesquisa; o terceiro bloco conteve perguntas da atual situação acadêmica e/ou profissional dos egressos, além das perguntas sobre contribuições proporcionadas pela participação no Observatório para sua formação na qualidade de pesquisador e para a atuação profissional.

O formulário foi enviado de julho a novembro de 2016. Ao final, foram obtidos trinta 30 (= $52 \%)$ respostas de sujeitos com faixa etária de 23 a 46 anos. Desses, seis são do núcleo UFOP, 12 do núcleo UECE e 12 do núcleo UNIFESP, em que, 20 são mulheres e dez homens. Pressupõe-se que a disparidade da quantidade de egressos do sexo masculino em relação ao sexo feminino talvez seja resultado do grande número de egressos advindos do curso de graduação em Pedagogia, um curso predominantemente feminino. Do total dos respondentes (30), quinze egressos (50\%) tinham formação inicial em Pedagogia, cinco em História, três em Ciências Biológicas, três em Educação Física, dois em Filosofia e dois em Letras Português.

Dezoito dos egressos ingressaram em 2013, o primeiro ano da pesquisa, sete em 2014 e dois em 2015; apenas um egresso relatou não se lembrar em que ano ingressou no OBEDUC. A maior parte dos integrantes ingressou na pesquisa por meio de convite (17) e os demais mediante seleção (13). O desligamento dos egressos iniciou ainda em 2014 quando sete integrantes saíram do grupo, dez se desligaram em 2015 e nove em 2016. Os egressos respondentes deste levantamento tinham formação em diferentes níveis: 16 eram graduandos, 13 mestrandos, um doutorando.

No que concerne à motivação para participar do Observatório, as respostas que apareceram com maior frequência foram o interesse na temática do projeto (11), seguida pela oportunidade de ter uma experiência em pesquisa (6), por aprender a desenvolver uma pesquisa (4), pela oportunidade de participar de uma pesquisa em rede (3), pelo interesse de aprofundamento teórico (3) e pelo proveito em uma experiência formativa inovadora (3). 


\section{autêntica}

Em meio às experiências que o Observatório proporcionou, uma delas foi a oportunidade de participar de eventos acadêmicos locais, nacionais ou até mesmo internacionais. Quando questionados sobre essa experiência, 23 egressos relataram haver participado de eventos com apresentação de trabalhos, composição de mesas e painéis; já sete responderam não ter participado de nenhum evento em razão do curto período que passou no Projeto ou por falta de oportunidade na época.

Como qualquer outro grupo de pesquisa, há sempre uma rotatividade de integrantes. No Projeto não foi diferente: 13 egressos afirmaram ter se desligado da pesquisa após o término do curso da graduação, mestrado ou doutorado; três responderam que o desligamento aconteceu em virtude da aprovação no curso de mestrado; cinco relataram ter tido dificuldades para conciliar as atividades da pesquisa com o trabalho e com isso ficaram impossibilitados de continuar; dois ingressaram em outra pesquisa; outros dois relataram que o desligamento se deu por motivos pessoais, não especificando; um por assumir cargo público; um por outra oportunidade de emprego; e, um informou que foi desligado pela coordenação.

Nas considerações dos egressos, as experiências mais marcantes durante a participação no Observatório foram: as reuniões, os seminários de estudos e discussões sobre a pesquisa, os estudos bibliográficos, os encontros contínuos com diálogos inquietantes, de exposição de pontos e contrapontos; o primeiro encontro na UNIFESP, organizar e receber os colegas, trocar ideias pessoalmente e a participação nos fóruns e encontros da pesquisa em Ouro Preto, Guarulhos e Fortaleza.

Um dos pontos marcantes mais ressaltados pelos egressos foi a realização do trabalho de campo: a etapa da coleta (formulários eletrônicos e entrevistas), a apuração de dados primários que fundamentaram a pesquisa (transcrições) e o tratamento dos dados mergulhando no mundo tecnológico com o uso do software Nvivo. Além disso, destacam a troca de conhecimentos com os colegas e professores, junto com os coordenadores dos núcleos, debatendo e estabelecendo os rumos da pesquisa.

As viagens para eventos também foram ressaltadas como oportunidades significativas no Observatório, bem como apresentação de trabalho; composição de mesas e painéis; a experiência de pesquisar em rede; as oficinas sobre questões de método e metodologia da pesquisa; a troca de experiências entre variadas áreas do conhecimento; as amizades firmadas; a gratificação de ver o brilho nos olhos dos professores supervisores ao trazerem suas reflexões a respeito da experiência de participação no PIBID; o estabelecimento de hipóteses e as trocas em torno dos temas da formação docente e desenvolvimento profissional; e o trabalho de pesquisa coletivo sobre inovação na Educação.

O crescimento acadêmico foi reconhecido por todos, o aprender a ser pesquisador, a ampliação de conhecimento e formação acadêmica, o aprendizado com as experiências dos colegas de outras escolas, bem como as discussões por vídeo-conferência com integrantes de outros estados. Os momentos foram marcados pela heterogeneidade de ideias, de olhares, firmando o lugar de cada um. Uma professora da Educação Básica relatou ainda que a experiência do Observatório proporcionou, de modo significativo, a convivência com uma universidade pública e a fez sentir-se parte dela.

No que se refere à atual situação acadêmica dos egressos, constatou-se que: nove estão participando de grupos de estudos e/ou pesquisa; seis cursando mestrado; três cursam doutorado; três estão na graduação e nove não se manifestaram. Esses dados evidenciam o grupo de pesquisa como experiência mobilizadora para o desenvolvimento e a formação de pesquisadores. 


\section{autêntica}

Quanto à situação profissional, 15 dos egressos afirmaram estar exercendo a docência, oito estão atuando em atividade educacional não docente, apenas um atuando em área não relacionada à educação e cinco relataram não exercer nenhuma atividade laboral atualmente. Portanto, constatou-se que $50 \%$ dos egressos do Observatório no momento em que responderam o levantamento se encontravam exercendo a docência.

Entre os egressos, 27 afirmaram ter interesse em participar de iniciativas similares a essa investigação, pois acreditam ser importante estar engajados em ações que promovam a pesquisa e a produção de conhecimento. Registraram, também, que essa experiência fortalece o repertório de conhecimento teórico e prático e proporcionando sua atualização. Apenas três egressos não participariam de uma experiência como essa novamente em razão do trabalho que exercem atualmente e da dificuldade de conciliar o tempo.

As considerações dos egressos sobre as contribuições do Observatório para sua formação e atuação profissional foram classificadas em dois grupos: os que ressaltam o papel das atividades do grupo de pesquisa para a formação profissional como pesquisadores (13), e aqueles que ressaltam as contribuições da participação para a melhoria de sua atuação em sala de aula, ou no cotidiano escolar (15).

O primeiro grupo exprimiu, entre outras contribuições, a oportunidade de uma formação fomentando os conhecimentos específicos, o despertar do interesse em atuar como pesquisador profissionalmente, o amadurecimento acadêmico e a ampliação do repertório teórico necessário ao trabalho do professor. Destacou, também, o aprendizado de desenvolver uma pesquisa, o estabelecimento de relações acadêmico-profissionais, a consciência de como a sua participação mais efetiva na pesquisa auxiliou a compreensão das mudanças necessárias à escola, assim como a ampliação do conhecimento necessário para a docência universitária.

O segundo grupo sublinhou, como principais contribuições da experiência do Observatório para seu trabalho em sala de aula como professor, o fortalecimento da formação pedagógica e a ampliação da experiência como docente da Educação Básica. Ressaltou, ainda, que a experiência indicou os caminhos para a reflexão sobre a prática docente, possibilitou a elaboração coletiva de conhecimentos específicos da profissão, trouxe a possibilidade de unir as discussões teóricas dos estudos sobre inovação pedagógica com a sala de aula, bem como a consciência da necessidade de formação continuada.

Os egressos relataram, também, que o conhecimento proporcionado ensejou outras perspectivas e atitudes ante a relação escola-sociedade, da formação e do desenvolvimento profissional docente, mudando o próprio modo de trabalhar em sala de aula.

No que diz respeito às contribuições da participação no Projeto na formação do pesquisador, com exceção de um (que não respondeu), os demais egressos relataram ter sido um momento muito importante, de crescimento, aprendizado, trocas, desenvolvimento do senso crítico e ampliação do repertório teórico. Para muitos, essa foi a primeira experiência de pesquisa que vivenciaram, e, pela primeira vez, tiveram oportunidade de estudar e aprofundar questões metodológicas de uma pesquisa individual e coletiva, o que acrescentou significativamente no percurso de cada sujeito.

Alguns egressos relataram, ainda, que foi um diferencial participar de uma pesquisa em rede cursando mestrado ou doutorado, pois muito da produção e do conhecimento, sobretudo das questões metodológicas, das teses e dissertações, foram aprendizados advindos das vivências no grupo.

Foi a experiência do Observatório que possibilitou para muitos a primeira pesquisa coletiva, a primeira ida a campo, a primeira realização de entrevistas, o primeiro contato com o software Nvivo e as primeiras 


\section{autêntica}

transcrições. Em suma, a etapa da coleta, organização e análise dos dados foi determinante na formação dos egressos, uma vez que os conhecimentos adquiridos nesse período proporcionaram conhecer e participar das distintas fases de uma pesquisa, desenvolver habilidades de escrita, registros, métodos, instrumentos, manuseio de softwares, dentre outros procedimentos que permitiram compreender e ressignificar o trabalho do pesquisador.

Além da etapa de coleta dos dados, outro ponto ressaltado foi a organização do trabalho, o modo como a equipe conduziu todo o processo em grupo, as reuniões simplificadas às apresentações de trabalho, a sintonia e o comprometimento dos integrantes -tudo foi um aprendizado coletivo. A participação em uma pesquisa em rede ampliou a bagagem teórica sobre desenvolvimento profissional docente e inovação pedagógica e metodologias de pesquisa.

Por fim, sobre a participação em uma pesquisa em rede com três universidades envolvidas, os egressos responderam ter sido um desafio, uma experiência inovadora, um exercício do trabalho de colaboração, diálogo, respeito, intercâmbios culturais de saberes pessoais e profissionais, trocas valiosas e importantes relações interpessoais estabelecidas, na qual desenvolveram um projeto com vários pesquisadores de instituições com distintas realidades e geograficamente distantes.

Estar em contato com outras instituições foi um fato percebido como um privilégio pelos egressos, pois proporcionou experiências e aprendizados diferentes, contribuiu para melhor compreender o PIBID como ação governamental. Para muitos egressos, essa foi a maior experiência como pesquisador, dado o grande número de sujeitos, pesquisadores e regiões envolvidas. Foi também um momento complexo e de aprendizado sobre o respeito pelo tempo do outro, de pensar, sentir, questionar e vivenciar a abrangência do mundo da pesquisa em rede.

Em síntese, os egressos reconhecem o grupo de pesquisa como uma experiência de formação, ressignificação de saberes e aprendizados que ensejou momentos ímpares de amadurecimento, desafios, produção de conhecimento, estabelecimento de relações, motivação na continuidade da formação e mudança nas práticas pedagógicas. 


\section{autêntica}

\section{CONSIDERAÇÕES FINAIS}

A reflexão que aqui trazemos apresenta um conjunto de reflexões construídas a partir das experiências desenvolvidas por um grupo de bolsistas do OBEDUC. A proposta desenvolvida entre os anos de 2013 a 2016 por meio do projeto de pesquisa "Desenvolvimento profissional docente e inovação pedagógica: estudo exploratório sobre contribuições do PIBID" constituiu-se como uma Rede de formação que extrapolou o objetivo primeiro de ser uma pesquisa realizada em âmbito nacional, na busca de iidentificar aspectos da experiência formativa no programa governamental de incentivo a formação do futuro professor, ao qual possa ser atribuídas contribuições para fomentar uma profissionalidade docente que supere a racionalidade técnica e que posicione ao professor da Educação Básica processo formativo no qual se torne sujeito produtor de saberes sobre sua profissão; favorecer a pesquisa em rede sobre desenvolvimento profissional docente, consolidando grupos de pesquisa nessa área vinculados a Programas de Pós-Graduação em Educação no eixo Nordeste e Sudeste; e organizar dados educacionais regionais no âmbito do eixo Nordeste e Sudeste, produzidos pelo INEP, como subsídio ao aprofundamento de estudos sobre o perfil das escolas e dos professores que compõe o PIBID, assim como para fomentar novos estudos.

Ao longo desse processo foram revisitados e até mesmo (re)construídos conceitos como de pesquisa colaborativa, trabalho em equipe, autoformação e formação continuada, assim como, discussões sobre o PIBID, a formação docente e as inovações na prática de ensino que se materializaram em diversas situações no cotidiano da pesquisa, desafiando graduandos, mestrandos, professores da Educação Básica e coordenadores a um movimento contínuo de diálogo e reflexão.

\section{REFERENCIAS}

ANDRÉ, Marli Eliza Dalmazo Afonso de. Práticas inovadoras na formação de professores. Campinas, São Paulo: Papirus, 2016.

ANDRÉ, Marli Eliza Dalmazo Afonso de; PESCE, Marly Krüger de. A formação do professor pesquisador na perspectiva do professor formador. Formação Docente, vol. 04, nº 07, jul./dez., 2012.

ANDRÉ, Marli Eliza Dalmazo Afonso de.. Ensinar a pesquisar. Como e para quê? In: Anais do ENDIPE. Recife, 2006, p. 221-234.

ANDRÉ, Marli Eliza Dalmazo Afonso de. Pesquisa, formação e prática docente. In: (Org.). O papel da pesquisa na formação e na prática dos professores. $5^{\text {a }}$ ed. Campinas, São Paulo: Papirus, 2006a, p.55-69.

ANDRÉ, Marli Eliza Dalmazo Afonso de.. O papel mediador da pesquisa no ensino da didática. In: OLIVEIRA, M. R. (Orgs.). Alternativas do ensino da Didática. Campinas, São Paulo: Papirus, 1997, p.1936.

BRASIL. CNE. Resolução CNE/CP n¹, de 18 de fevereiro de 2002. Diretrizes Curriculares Nacionais para a Formação de Professores da Educação Básica, em nível superior, curso de licenciatura, de graduação plena. Brasília, 2002.

BRASIL.. CNE. Resolução $n^{\circ} 2$, de $1^{\circ}$ de julho de 2015. Diretrizes Curriculares Nacionais para a formação inicial em nível superior (cursos de licenciatura, cursos de formação pedagógica para graduados e cursos de segunda licenciatura) e para a formação continuada. Brasília, 2015. 


\section{DOCENTE}

\section{autêntica}

BRASIL. CAPES. DEB. Relatório de gestão PIBID 2009 - 2013. Brasília, 2013.

BRZEZINSKI, Iria. A formação e a carreira de profissionais da educação na LDB n 9.394/96: possibilidades e perplexidades. In: (Org.). LDB interpretada: diversos olhares se entrecruzam. 10ª ed., São Paulo: Cortez, 2005, 141-158

CLÍMACO, João Carlos Teatini de Souza; NEVES, Carmen Moreira de Castro; LIMA, Bruno Fernandes Zenobio de. Ações da Capes para a formação e a valorização dos professores da Educação Básica do Brasil e sua interação com a pós-graduação. Revista Brasileira de Pós-Graduação, v.9, n 16, abril. Brasília, CAPES, 2012, p. 181-209.

COCHRAN-SMITH, Marilyn; LYTLE, L. Susan. Relations hipsof knowledge and practice: teacher learning in communities Sage Journals online. Reviewof Research in Education, Jan. 1999. Disponível em: Acesso em: 15 jul. 2011.

DEMO, Pedro. Pesquisa: principio científico e educativo. 12ª ed. São Paulo: Cortez ed. 2006.

DOURADO, Luis Fernando. Diretrizes Curriculares Nacionais para a formação inicial e continuada dos profissionais do magistério da Educação Básica: concepções e desafios. Educação \& Sociedade, Campinas, v. 36, n. 131, p. 299-324, abr.-jun., 2015.

MORIN, Edgar. Ciências com Consciência.Publicações Europa-América, abril de 1994

FARIAS, Isabel Maria Sabino de, JARDILINO, José Rubens Lima; SILVESTRE, Magali Aparecida. Aprender a ser professor: aportes de pesquisa sobre o PIBID. Jundiaí: Paco, 2015.

FARIAS, Isabel Maria Sabino de, JARDILINO, José Rubens Lima; SILVESTRE, Magali Aparecida. Contribuições do OBEDUC como pesquisa em rede para a formação do professor. Revista Educação Matemática em Foco, Paraíba, vol. 5, nº 1, jan/jun. 2016, p. 13-29.

GALIAZZI, Maria do Carmo; MORAES, Roque. Educação pela pesquisa como modo, tempo e espaço de qualificação da formação de professores de ciências. Ciência \& Educação, Bauru, v. 8, n. 2, 2002.

HOUAISS, Antônio; VILLAR, Mauro de Salles. Dicionário Houaiss da língua portuguesa. Instituto Antônio Houaiss de Lexicografia e Banco de Dados da Língua Portuguesa S/C Ltda. $1^{\text {a }}$ Ed. Rio de Janeiro: Objetiva, 2009.

LATOUR, B. Ciência em Ação. Como seguir cientistas e engenheiros sociedade afora. São Paulo, UNESP, 2000.

LÜDKE, Menga. A complexa relação entre o professor e a pesquisa. In: ANDRÉ, Marli. (Org.). O papel da pesquisa na formação e na prática dos professores. $5^{\text {a }}$ ed., Campinas: Papirus, 2006.

LÜDKE, Menga. O professor, seu saber e sua pesquisa. Educação \& Sociedade, Campinas: Unicamp, v. 22, n. 74, p. 77-96, abr. 2001.

CASTELL, Manuel. Sociedade em Rede. Lisboa: Fundaçao Calouste Gulbenkian, 2002 


\section{autêntica}

CASTELL, MANUEL. The Rise of the Network society. London: John Wiley \& SONS, 2005

McLUHAN, Marshall. A Galáxia de Gutemberg. A formação do homem tipográfico. Rio de Janeiro: Companhia Editora Nacional, 1972

MINAYO, Maria Cecília de Souza (Org.). Pesquisa Social. Teoria, método e criatividade. 18a ed., Petrópolis, Rio de Janeiro: Vozes, 1994.

RAUSCH, Rita Buzzi. Professor-pesquisador: concepções e práticas de mestres que atuam na educação básica. In. Rev. Diálogo Educ., Curitiba, v. 12, n. 37, p. 701-717, set./dez. 2012

SEVERINO, A.J. Competência técnica e sensibilidade ético-politica: O desafio da formação de professores. Cadernos FEDEP. Fórum de Defesa da Escola Pública. São Paulo, n.1, p.10-23. 2002

ZEICHNER, K. M. Para além da divisão entre professor-pesquisador e pesquisador acadêmico. In: GERALDI, C. M. G. et al. Cartografias do Trabalho Docente: professor(a) pesquisador(a). 1ª. Reimpressão. Campinas, São Paulo: Mercado das Letras; Associação de Leitura do Brasil - ALB, 2000, p. 207-236 